\title{
LA CORRECCIÓN FUNCIONAL Y EL STARE DECISIS COMO ALTERNATIVAS PARA LA LEGITIMIDAD DEL CONTROL CONSTITUCIONAL EN DEMOCRACIAS DISFUNCIONALES
}

María Dolores Collazos Velasco*

\begin{abstract}
RESUMEN: Por dificultad contra mayoritaria se entiende el problema que suscita que en un sistema democrático las leyes, como decisiones tomadas por el Congreso y respaldadas por las mayorías, puedan ser declaradas inexequibles por el Tribunal Constitucional, siendo esta una minoría no electa, en ejercicio del control constitucional. Dicha labor supone interpretar la Constitución, y para el Tribunal Constitucional Alemán y la teoría constitucional de John Ely debe realizarse observando la dignidad democrática de la ley. Ahora bien, el control constitucional en democracias disfuncionales puede justificarse en razón del respeto que debe guardar el juez constitucional por las funciones a él encomendadas (corrección funcional), y al stare decisis, debiendo el Tribunal Constitucional hacer un buen ejercicio de argumentación jurídica cuando considere necesario apartarse del precedente.
\end{abstract}

\section{PALABRAS CLAVE: Control constitucional - legitimidad - dificultad contra mayoritaria - corrección funcional.}

ABSTRACT: Counter-majority difficulty is understood as the problem that provokes that laws in a democratic system, as decisions taken by Congress and backed by the majority, can be declared unenforceable by the Constitutional Tribunal, it being a non-elected minority, exerting constitutional control. This means interpreting the Constitution, and for the German Constitutional Tribunal and John Ely's constitutional theory, it should be done in observance of the democratic dignity of law- But now, constitutional control in dysfunctional democracies can be justified owing to the respect that the constitutional judge must have for the entrusted duty(dutiful correction) and for stare decisis, having the Constitutional Tribunal to make a good exercise of legal argument when considering necessary to withdraw form a precedent.

\section{KEYWORDS: Constitutional control - legitimacy - counter-majority difficulty - correction dutiful.}

\section{Introducción}

El devenir de la vida jurídica moderna ha hecho del control de constitucionalidad "une pièce classique de l'arsenal constitutionnel', y hoy es una de las principales funciones de los

\footnotetext{
* Estudiante egresada de la Facultad de Derecho de la Universidad del Cauca, Popayán, Colombia.

1 "Una pieza clásica del arsenal constitucional" se encuentra en el artículo de BÉGUiN, Jean-Claude. Le Contròle de la Constitutionnalité des lois en République Fédérale d'Allemagne. En: FERnÁNDEZ SEGADO, Francisco. Evolución Histórica y Modelos de Control de Constitucionalidad. Y en: Garcia Belaunde, D. Y Fernández SEgado, F. (coordinadores). La Jurisdicción Constitucional en Iberoamérica. Madrid, Editorial Dykinson, 1997, p. 45.
} 
Tribunales Constitucionales como defensores del orden constitucional ${ }^{2}$. Su importancia en la Justicia Constitucional es indiscutible y merced a ese protagonismo ha sido blanco de múltiples críticas, en medio de las cuales alza la voz aquella según la cual el control constitucional y la democracia son irreconciliables. Básicamente, quienes sostienen este punto de vista afirman que cuando los jueces ejercen el control de constitucionalidad se rompe el principio central del ideario democrático, según el cual:

"las decisiones políticas deben ser adoptadas mediante consenso popular y no mediante la decisión de los Tribunales, que no tienen sino de modo reflejo -y muy mediatizadamente- cierta legitimidad democrática"3.

En lo sucesivo, se revisarán las razones para la formulación de objeciones al control constitucional en un sistema democrático, para luego y a través de la mención a la experiencia del Tribunal Constitucional alemán y al jurista estadounidense John Ely, superar las críticas anteriormente nombradas. Todo lo cual permitirá analizar si dicha fórmula es susceptible de ser trasladada a sistemas en los que el "ser" de la democracia ha sufrido una distorsión en relación con su "deber ser". Dicho lo anterior, se propondrán el principio de corrección funcional y el stare decisis como alternativas para revestir de legitimidad al control constitucional en el sistema en cuestión.

1. El Control Constitucional: entre la objeción democrática y la dificultad contra mayoritaria.

Un buen punto de partida para contextualizar la dificultad contramayoritaria es definir el control constitucional. Pues bien, este último consiste en la vigilancia que el Tribunal Constitucional ejerce sobre las leyes aprobadas por el Parlamento persiguiendo que respeten los derechos y libertades que la Constitución garantiza. Víctor Ferreres Comella ha abordado esta definción en términos de la función que tiene a cargo el juez constitucional, cuál es "controlar que las leyes no contradigan la Constitución. Más exactamente: se encarga de controlar que determinadas disposiciones que integran el texto de una ley sean compatibles con el sistema de disposiciones que integran el texto constitucional"4.

Adicionalmente, el juez constitucional ejerce esta función de manera privativa pues ostenta el "monopolio del rechazo", expresión referida a que "solo él puede declarar, con efectos generales,

\footnotetext{
${ }^{2}$ Hans Kelsen defendió frente a su colega Carl Schmitt la idea de que el Tribunal Constitucional es el guardián de la Constitución por excelencia, señalando que cuando éste "rechaza la aplicación de una ley inconstitucional y anula consecuentemente su validę,para un caso concreto opera realmente como garante de la constitución, aún cuando no se le confiera el altisonante título de 'defensor de la Constitución'”. KELSEN, Hans. ¿Quién debe ser el defensor de la constitución? Segunda edición, España, Editorial Tecnos, 1995, p. 17.

3 Alvarez Alvarez, Fernando D., "Legitimidad Democrática y Control Judicial de Constitucionalidad (Refutaciones Al Denominado Carácter Contramayoritario Del Poder Judicial)", en Revista de actualidad jurídica Díkaion. [En línea]. Facultad de Derecho, Universidad de La Sabana, número 12, 2003. Disponible en la World Wide Web: $<$ http://dialnet.unirioja.es/servlet/articulo?codigo $=2107653>$.

${ }^{4}$ Ferreres Comella, Víctor. Justicia Constitucional y Democracia. Madrid, España, Centro de Estudios Políticos y Constitucionales, 1997, p.18.
} 
que determinado precepto de Ley es contrario a la Constitución"5. "En la terminología alemana: el único monopolio del Tribunal Constitucional es el monopolio de rechazo (verwerfung) de la Ley inconstitucional'. En definitiva se trata esta de una labor interpretativa. "La interpretación constitucional es concretización (Kokretisierung). Precisamente lo que no aparece de forma clara como contenido de la Constitución es lo que debe ser determinado mediante la incorporación de la realidad de cuya ordenación se trata" 7 . Si la ley sostuviera un diálogo con la Constitución sin ambas entenderse, la ley terminaría siendo declarada inexequible. La cuestión es que los términos bajo los cuales habría de desarrollarse esa conversación los concreta el Tribunal Constitucional. Significando lo anterior que estos tribunales se perfilan como los grandes intérpretes de la Carta de su respectivo país ${ }^{8}$, demostrando plena vigencia la célebre frase que pronunciara el ex presidente de la Suprema Corte de los Estados Unidos, Charles Evans Hughes, siendo gobernador del Estado de Nueva York: "vivimos bajo una Constitución; mas la Constitución es lo que los jueces dicen que es" 9 .

Aceptando que el juicio de constitucionalidad va más allá de la simple comparación de una ley con la Constitución, pues se inmiscuye este en los terrenos de la interpretación, sobreviene la interrogante acerca de cómo los jueces constitucionales han de llevar a cabo esa tarea. De lo anterior se desprende que el margen para la existencia de libertad interpretativa significa un riesgo de lesionar el carácter democrático que ostenta la ley aprobada en el seno del Congreso, institución insigne de la Democracia. Es lo precedente razón para afirmar que el control constitucional genera cierta desconfianza que dice relación con su carácter poco democrático. Cabe preguntarse entonces ¿qué legitima dentro de la Democracia que una minoría no electa y políticamente irresponsable declare inexequible una ley aprobada por la mayoría políticamente responsable? Alexander Bickel bautizó la cuestión como "la dificultad contra la mayoría"10 refiriéndose al problema que representa buscar la legitimidad, desde el punto de vista democrático, del ejercicio del control judicial de la constitucionalidad de la Ley. En palabras del autor: "La dificultad radical es que el control judicial en nuestro sistema es una fuerza contra-mayoritaria (...) Cuando la Corte Suprema declara inconstitucional una Ley o una acción de un Ejecutivo electo, tuerce la voluntad de los representantes del pueblo real de aquí y ahora; ejerce control, no en nombre de la mayoría sino en su contra(...)"11, de modo que la institución parece haberse diseñado para coartar las decisiones de órganos políticos conformados según la voluntad de los electores.

\footnotetext{
${ }^{5}$ Ibid., p. 17.

${ }^{6}$ GARCia De Enterria, Eduardo. La Constitución como norma y el Tribunal Constitucional. Tercera edición, Madrid, España, Editorial Civitas, S.A., 1985, p. 66.

${ }^{7}$ Hesse, Konrad. "La Interpretación constitucional”. En sus: Escritos de Derecho Constitucional. Primera edición al español, Madrid, España, Centro de Estudios Constitucionales, 1983, p. 43.

${ }^{8}$ Roberto Gargarella se pronuncia a favor de esta idea y señala que "los jueces hacen mucho más que efectuar una "mera lectura" de la Constitución. En algunos casos, los jueces "incorporan" al texto soluciones normativas que no estaban -al menos explícitamente- incorporadas en el mismo". GARGARELLA, Roberto. La Justicia frente al Gobierno. Sobre el carácter contramayoritario del poder judicial. Barcelona, Editorial Ariel S.A, 1996, p. 56.

${ }_{9}$ CARrillo Flores, Antonio. Prologo a la primera edición. En: Huges, Charles Evans. La Suprema Corte de los Estados Unidos. Segunda edición en español, México D.F, Fondo de Cultura Económica, 1971, p. 7.

${ }^{10}$ LOPEZ DAZA, Germán Alfonso. La Justicia Constitucional Colombiana: ¿Un gobierno de los Jueces? Colombia, Editorial Universidad Surcolombiana, 2005, p. 92.

${ }^{11}$ BiCKel, Alexander. The Least Dangerous Branch. En: Ferreres Comella, Víctor. Justicia Constitucional y Democracia. Madrid, Centro de Estudios Políticos y Constitucionales, 1997, p. 41.
} 
Aún cuando, la dificultad contramayoritaria gira alrededor de la democracia estadounidense específicamente, la teoría constitucional la ha adoptado para sí convirtiéndola en un reproche común a la justicia constitucional en general. Entendiendo las condiciones que rodean el proceso democrático que precede a la conformación del Congreso, a saber: “i) $L a$ elección popular a la que acuden los ciudadanos libremente y en ejercicio de su derecho al sufragio; ii) Representación de las mayorías; iii) Responsabilidad política"12, la razón de la crítica se hace evidente, pues son estos rasgos no compartidos por la Justicia Constitucional; una minoría no electa e irresponsable políticamente tiene el monopolio del rechazo. Por ende junto a la dificultad contramayoritaria se levanta la objeción democrática.

Así las cosas, "nuestra sensibilidad democrática del siglo XXI no parece permitirnos aceptar acríticamente que el monopolio del rechazo se encuentre en manos de funcionarios que no han sido elegidos por el pueblo"13. La legitimidad del control constitucional en la democracia sigue a la espera de una respuesta, la que necesariamente estará permeada por las específicas condiciones históricopolíticas del sistema jurídico en cuestión; en este sentido, la experiencia del Tribunal Constitucional de Alemania y los planteamientos del teórico norteamericano John Ely aportan importantes elementos.

2. El Tribunal Constitucional alemán y la teoría constitucional de John Ely: dos caminos en la búsqueda de la armonía del control constitucional y la democracia.

El Tribunal Constitucional Federal Alemán (Bundesverfassungsgericht) apuesta por el principio de la interpretación de la ley conforme a la Constitución para superar la objeción democrática, pero es imposible acercarse a este concepto sin referirse primero a las experiencias de la posguerra. La Segunda Guerra Mundial dejó a Alemania sumida en la miseria y el desconocimiento de las instituciones democrático-constitucionales, por lo que durante la reconstrucción económica tanto el Parlamento como el Gobierno se vieron obligados a tomar medidas tendientes a superar el caos que consumía al país. Como expresión de esos esfuerzos fue proferida la Ley de Formación e Incremento de Precios-Preisgesetz-

Posteriormente, el artículo $2^{\circ}$ de dicha ley fue objeto de una demanda constitucional de nulidad ante el Tribunal Alemán, debiendo enfrentarse al dilema de considerar que conforme a la Ley Orgánica del Tribunal Constitucional, el artículo demandado era efectivamente inconstitucional, no obstante la Ley de Formación e Incremento de Precios estaba siendo efectiva en el proceso de reconstrucción y servía como telón de fondo para el perfeccionamiento de actos jurídicos enteramente compatibles con su finalidad, y en últimas, coherentes con las apremiantes necesidades de aquella coyuntura histórica.

El Tribunal superó la dificultad señalando que la Ley era constitucional interpretándola de manera restrictiva y atendiendo a la especial situación que atravesaba Alemania. Sin embargo, lo verdaderamente interesante es que ésa fue la primera vez que el Tribunal Constitucional Alemán expresó la fórmula que signaría su producción jurisprudencial

12 Rodríguez Peñaranda, María Luisa. Minorías, Acción Pública de Inconstitucionalidad y Democracia Deliberativa. Colombia, Universidad Externado de Colombia, 2005, p. 18.

13 Alvarez Alvarez, Fernando D. op.cit (n. 3). 
en el futuro: "cuando una norma legal da lugar a ser interpretada de varias maneras, una inconstitucional y otra constitucional, deberá preferirse la interpretación que esté totalmente acorde con la Constitución"14. Se trata del principio de la interpretación de la Ley conforme a la Constitución.

El citado principio supone que, ante la duda de la constitucionalidad de la Ley, debe indagarse primero si ésta resulta constitucional en algún sentido de entre todos los sentidos interpretativos posibles, $y$, de ser así, ha de preferirse éste ante la declaratoria de inconstitucionalidad; en otras palabras, "impide a la Corte excluir del ordenamiento una norma cuando existe por lo menos una interpretación de la misma que se concilia con el texto constitucional"15.

Advirtiendo el poder que esta fórmula otorga al intérprete de la ley, el mismo Tribunal Constitucional Alemán ha establecido que al juez no le está permitida la implementación del principio para dar un significado distinto a una ley cuyo sentido resulta claro y evidente, o lo que es lo mismo, so pretexto de una interpretación conforme a la Constitución no se puede "cambiar o falsear la finalidad del legislador en un punto esencial"16; en ese sentido la Sentencia de 7 de mayo de 1953 -BVerfGE 2, 66 [282] señaló que "en caso de duda se ordena una interpretación conforme con la Constitución" para mas adelante añadir que "esto por supuesto no implica que se pueda dejar de lado la finalidad de la ley" ${ }^{17}$.

El segundo camino es el transitado por el jurista estadounidense John Ely, cuya teoría constitucional se ha convertido en un clásico de la literatura jurídica de ese país. Ely parte la oposición histórica entre los constitucionalistas alrededor de cómo interpretar la Constitución, y en ella distingue entre textualismo e interpretación libre (interpretivism y non-interpretivism). El sector que se inclina a favor del textualismo defiende la reducción de la libertad interpretativa de los jueces en asuntos de constitucionalidad en favor de la aplicación exacta del articulado Constitucional; por el contrario, los partidarios de la interpretación libre abogan por la autonomía del juez en la aplicación de normas que no se hallan en el texto constitucional y que deben ser descubiertas. Ante la pregunta ¿qué justifica válidamente que un Tribunal Constitucional invalide una disposición del Congreso? un textualista respondería que la mencionada Ley del Congreso contradice una disposición claramente expresada en la Constitución y el Tribunal solo estaría aplicándola textualmente. El autor resalta la fuerza de esta tendencia mediante dos razones conexas entre sí: la primera es que se adapta con facilidad a la noción tradicional de lo que entendemos acerca de lo que es el Derecho y cómo funciona; y la segunda, que se reconcilia fácilmente con la teoría democrática sobre la cual descansa el sistema Norteamericano ${ }^{18}$ y la mayoría de sistemas en occidente.

\footnotetext{
${ }^{14}$ LANDA ARroyo, Cesar. "Justicia Constitucional y Political Questions”. Revista Pensamiento Constitucional. <En línea $>$ Volumen 7, número 7, 2000, pp. 111-140. Disponible en la World Wide Web: $<$ http://www.pucp.edu.pe/revista/pensamiento_constitucional/?art01.htm>

${ }^{15}$ Gonzalez Solano, Edgar. Sentencias Manipulativas e Interpretativas y Respeto a la Democracia en Colombia. Colombia, Universidad Externado de Colombia, 2000, p. 31.

${ }^{16}$ SCHWABE, Jürgen. Cincuenta Años de Jurisprudencia del Tribunal Constitucional Federal Alemán. Bogotá, Ediciones Jurídicas Gustavo Ibáñez, 2003, p. 4.

${ }^{17}$ Ibid., p. 3.

${ }^{18}$ ElY, John Hart. Democracia y Desconfianza, Una Teoría del Control Constitucional. Bogotá, Colombia, Siglo del Hombre Editores, Universidad de los Andes, 1997, p. 22.
} 
Ahora bien, aunque el textualismo resulta llamativo, no por eso debe adoptarse sin ciertas reservas. La versión estándar supone que la Constitución está conformada por cláusulas de fácil ubicación en el texto, unidades autosuficientes que deben interpretarse con apego al lenguaje de su redacción y la historia legislativa previa a su adopción; pero ello entraña una serie de problemas. Uno de ellos es que mediante el textualismo se permite que personas que vivieron hace uno o dos siglos sigan teniendo poder ante los tribunales y terminen decidiendo sobre generaciones presentes y futuras. Por otra parte, el lenguaje mediante el cual se expresa la Constitución no es uniforme respecto a su especificidad, y si asumimos que el lenguaje es la fuente principal en donde han de buscarse las intenciones de los redactores, la falta de claridad en él representa una barrera difícil de sortear para el textualismo: ¿cómo aplicar textualmente un texto que no es claro? Para esclarecerlo es posible referirse al propósito histórico de la cláusula sub examine, pero los vacíos de la historia legislativa son tantos y tan profundos que lo más importante sigue siendo el lenguaje ${ }^{19}$. En definitiva, insistir en el textualismo significa insistir en que "la función judicial quede reducida a la función puramente mecánica de aplicar las reglas impuestas desde fuera y de que solo sirva de portavoz de la voluntad popular que predomina en cada instante, lo cual no corresponde a una concepción progresiva del Derecho". ${ }^{20} \mathrm{El}$ arribo de la interpretación libre parece inminente.

La interpretación libre tradicionalmente ha sostenido que los jueces, al interpretar la Constitución, no deben sentirse temerosos de descubrir, identificar, e implantar valores de índole fundamental con el fin de anteponerlos en el ejercicio de articular la Constitución; en palabras del mismo Ely:

"la Corte suprema debiera satisfacer las disposiciones abiertas de la Constitución mediante la identificación e imposición a las ramas políticas de aquellos valores que, según una u otra fórmula, son verdaderamente importantes o fundamentales." 21

Si bien al juez se le permite referirse a fuentes alternativas al texto mismo, ahora la cuestión es el método de descubrimiento de tales valores. En medio de la libertad que adquiere el juez, Ely acepta, como la mayoría de los autores, que el talón de Aquiles de la interpretación libre es la objeción democrática. Si tal objeción versa sobre el hecho de que "un cuerpo que no es electo y no es políticamente responsable de otra manera significativa, les está diciendo a los representantes elegidos por el pueblo que no pueden gobernarse como lo desean" 22 , un partidario de la interpretación libre no podría explicar tal intromisión con la misma propiedad de un textualista sin ser criticado por la falta de seguridad que implica interpretar libremente la Constitución. Inevitablemente sobrevendría la acusación de que el control constitucional, bajo el esquema planteado por la libre interpretación, es una institución contraria a la democracia.

\footnotetext{
${ }^{19}$ Para Ely el mejor ejemplo de esto es lo que sucede con la enmienda novena de la Constitución de Estados Unidos, y dice: "Sería un golpe bajo anotar que no bay historia legislativa que indique especificamente la intención de que la enmienda novena bubiera de ser aplicada judicialmente" Ibíd., p. 59.

${ }^{20}$ Pound, Roscoe. El Espiritu del Common Law. Barcelona, España, Casa editorial Bosch, 1954, p. 94.

${ }^{21}$ ELY, John Hart. op.cit (n. 18).

22 Ibid., p. 23.
} 
La anterior acusación es muy grave y negarla no es tarea fácil, especialmente tratándose de sociedades que, como la de Estados Unidos -y los países latinoamericanos en general-, han elegido la democracia representativa como forma de gobierno. En el caso que ocupa a Ely, el "desarrollo constitucional durante el siglo pasado -hoy antepasado- fortaleció entonces sustancialmente el compromiso original de controlar a través de la mayoría a los gobernados" 23 y esa idea jamás ha sido cuestionada.

Así las cosas, es una verdad que la política norteamericana solo se explica en función de las mayorías, pero esta verdad admite otra, y es que cuando la mayoría no halla obstáculos en el manejo de la política ni en el establecimiento de sus propios lineamientos gubernamentales, fácilmente puede emprender acciones para beneficiarse dejando de lado las minorías. Si bien es cierto que el gobierno ilimitado de las mayorías es peligroso para las minorías, es más peligroso aún proteger a estas minorías mediante la aplicación de una Constitución no escrita por parte de los jueces ${ }^{24}$, por lo que el reto consistiría en proteger a las minorías mediante estrategias que no riñan con el principio democrático que sustenta a las mayorías, y aunque el textualismo parece ser la solución más adecuada, presenta serios problemas que se igualan a las dificultades de hallar una fuente externa de valores que dé contenido a la Constitución.

Hasta aquí las opciones para el Tribunal Constitucional norteamericano parecen ser solamente dos: textualismo e interpretación libre. Sin embargo, Ely ve una tercera vía para superar la objeción democrática. Para él, si bien es cierto que la Constitución Norteamericana necesita contenidos, la imposición de valores no ha de ser la única manera de otorgárselos, pues existe otra alternativa consistente en el deseo constante que debe atravesar a la Corte Suprema (o Tribunal Constitucional) de cuidar que el proceso de conformación de la voluntad política sea accesible a todos en condiciones de igualdad, por diferentes que sean sus puntos de vista. Esto está directamente relacionado con la necesidad de evitar la aprobación de iniciativas contentivas de impedimentos para el acceso de las minorías a los procesos democráticos basándose en prejuicios ${ }^{25}$.

Ely pretende reorientar el control constitucional como una forma de expresión que los Tribunales Constitucionales solo deben utilizar cuando se trate de leyes que recortan el acceso a la participación en el debate político, que dificultan la representatividad o que imponen prejuicios en contra de las minorías. Ante la pregunta ¿cuándo está justificado el control constitucional por parte del Tribunal Constitucional?, un partidario de Ely respondería que el control constitucional y la democracia son irreconciliables a menos que ese control sea ejercido para proteger el proceso democrático. En el mismo sentido se ha pronunciado Bruce Ackerman, para quien:

\footnotetext{
${ }^{23}$ Ibid., p. 25.

${ }^{24}$ Ibid., pp. 12-17

${ }^{25}$ Este enfoque fue expresado por primera vez en la célebre nota de pie de página de la sentencia United States vs. Carolene Products, proferida por la Corte Suprema de los Estados Unidos en 1938. "El párrafo segundo sugiere que es una función apropiada de la Corte garantizar el funcionamiento de la maquinaria del gobierno democrático sea adecuado, asegurarse de que los canales de participación y de comunicación políticas se mantengan abiertos. El párrafo tercero sugiere que la Corte debiera ocuparse asimismo de lo que las mayorías le hacen a las minorias, mencionando de manera especial las leyes "dirigidas a" minorías religiosas, nacionales y raciales y a aquellas infestadas de prejuicios contra ellas." Así, la nota de pie de página de la sentencia constituye una invitación no a reflexionar sobre la importancia de ciertos valores sustantivos sobre otros, sino sobre si la oportunidad de acceder a la conformación de la voluntad política ha sido indebidamente coartada para algunos. ELY, John Hart. op.cit (n. 18), p. 100.
} 
“darle a los políticos plena libertad para controlar los términos bajo los cuales ellos serán desafiados electoralmente conlleva un obvio peligro. ¿Qué les impedirá manipular este poder de manera que perjudiquen injustamente a sus rivales, quizás hasta el punto en que el proceso electoral se torne una parodia?. Aquí es donde entran los jueces"26.

Proteger el proceso democrático implica abrir los canales políticos, defender derechos como el derecho al sufragio, a la libre asociación o la libertad de expresión en torno a la igualdad, y encausar a los legisladores hacia la aprobación de disposiciones que traten por igual mayorías y minorías. $\mathrm{Al}$ respecto, Ely concuerda en que:

“desbloquear las obstrucciones al proceso democrático es de lo que debería ocuparse primordialmente el control judicial, y la negación del sufragio pareciera ser la obstrucción por excelencia. Otras prácticas que van al núcleo del derecho de la gente a elegir a sus representantes y expresar sus preferencias, son la negación de un lugar en la tarjeta electoral a los partidos minoritarios y la negación a posesionar a los representantes elegidos por el pueblo"27.

El autor defiende su teoría principalmente desde tres frentes. El primero de ellos es su particular visión de la Constitución de Estados Unidos. Para él, dicho texto no es un agregado de valores sustantivos sino un tratado en donde la selección y ajuste de éstos "se deja casi enteramente al proceso político, y el documento se ocupa más bien, de manera abrumadora, de la equidad procedimental en la resolución de los conflictos individuales (procesos de autos), por una parte, y de lo que en general puede denominarse procesos de decisión”28, por lo que al interpretar una cláusula con ocasión del control constitucional, el juez no está imponiendo valores, sino que está siendo inspirado por el resto del documento. En segundo término, la forma de utilización del control constitucional que Ely propone es totalmente compatible con la democracia representativa y aplicarlo sería fácil para los Tribunales por estar acostumbrados a asuntos procesales. Un tercer argumento señala que la Corte estaría ajena a coyunturas políticas y por eso podría desempeñar esa labor con más propiedad que los políticos profesionales. ${ }^{29}$.

La pretendida igualdad entre mayorías y minorías no implica para Ely la imposibilidad de establecer distinciones mediante las leyes; más aún, admite que "buena parte del objetivo de la

\footnotetext{
${ }^{26}$ Ackerman continúa diciendo que los jueces "ofrecen un mecanismo institucional a través del cual las ambiciones manipuladoras de los actuales gobernantes pueden ser controladas". Pero se refiere específicamente a sistemas en los cuales ellos están estrictamente divorciados de coyunturas políticas, como se evidencia cuando prosigue: “(...) los jueces tienen asegurada una larga permanencia en sus cargos que no depende $[\mathrm{n}]$ de victorias electorales, pueden evaluar con una pretensión plausible de imparcialidad los esfuerzos de los representantes en ejercicio de componer fraudulentamente el sistema electoral.". En países en los cuales los jueces integrantes del Tribunal Constitucional ostentan ese cargo por un período definido (por ejemplo Colombia, en donde el periodo es de 8 años y una vez ha concluido su período nada les impide influir en política desde otras ramas del poder público), la propuesta de Ackerman en torno a la imparcialidad del juez constitucional perdería fuerza. ACKerman, Bruce. La Política del Diálogo Liberal. España, Editorial Gedisa, 1999, p. 148.

${ }^{27}$ ELY, John Hart. op.cit. (n. 18).p.146.

${ }^{28}$ Ibid., p. 112.

${ }^{29}$ Ibid., pp. 113-114
} 
mayoría de las leyes es clasificar a las personas para aplicarles un tratamiento diferencial, y en ocasiones seriamente diferencial'30, pero la igualdad que propone Ely está orientada a la igualdad de acceso a los mecanismos de participación, de manera tal que si una ley distribuye dicho acceso de forma inequitativa, la Corte debe reflexionar sobre los posibles motivos que tuvo el Legislativo para ello, y si por más que lo intente no puede explicárselo, sabrá que la democracia ha sido seriamente lesionada y su intervención mediante el control constitucional estará justificada. "La tarea de la Corte en estos casos es mirar el mundo como es, y considerar que razones pueden aducirse a favor de tal negación, sin tener en cuenta lo que en realidad la ocasionó. En la medida en que haya obstáculos, el sistema está funcionando mal y la Corte debería removerlos sin importar cómo se produjeron" 31 .

Pero el juez de Ely, que solo interviene cuando las leyes aprobadas se entrometan sospechosamente en derechos asociados al proceso democrático y atenten contra las minorías, no siempre es buena opción, especialmente en países cuyos procesos democráticos son sustancialmente diferentes al Estadounidense y donde la Constitución difiere en estructura a la de ese país. Las Constituciones latinoamericanas por ejemplo, no siempre se identifican con los procedimientos, y frecuentemente lo hacen con la consagración de valores sustantivos. Aún así, su teoría arroja datos tan valiosos e interesantes que son suficientes para no dejarla de lado.

Si en algo coinciden el Tribunal Federal de Alemania y su principio de la interpretación de la ley conforme a la Constitución y los planteamientos de John Ely, es en que descansan sobre el profundo respeto que debe observar un Tribunal Constitucional al examinar la constitucionalidad de la ley, elemento que no puede perderse de vista y será retomado más adelante. En efecto, hay un consenso más o menos general alrededor de la democracia como uno de los pilares fundamentales del sistema, y al menos en teoría, cada congresista está respaldado por un número considerable de votantes que ha acudido a los comicios libremente en ejercicio del derecho al sufragio; además, las iniciativas son aprobadas después de complejos y reglados procedimientos de discusión. Si no fuese de este modo, la legitimidad del Congreso sería una verdad a medias. El problema es que hay motivos para pensar seriamente que así es ${ }^{32}$.

3. La controvertible dignidad democrática de la ley y la frágil premisa de la representatividad.

Democracia y legitimidad son términos que por lo general se funden en una premisa que bien podría enunciarse como lo legítimo es lo democrático, y "al afirmar que 'el poder es del pueblo' se establece una concepción sobre las fuentes y sobre la legitimidad del poder" 33 . Sin

\footnotetext{
${ }^{30}$ Ibid., p. 168.

${ }^{31}$ Ídem.

${ }^{32}$ Carlos Restrepo Piedrahita explica la crisis de legitimidad que atraviesan los Congresos actualmente al señalar que como se trata del "órgano de más fácil visibilidad y enfoque -un reducido numero de personas que periódicamente se concentran en la capital, absolutamente desprovistas de toda fuerza material y de quienes la ciudadanía, espera todas las recetas indispensables para su bienestar por el atributo mágico que se les supone o exige como padres de la patria- vive expuesto a implacable enjuiciamiento". Véase así: RESTREPO PIEDRAHITA, Carlos. Esquicio para una perspectiva bistórica del Congreso en Colombia. Bogotá, Universidad Externado de Colombia, 1986, pp. 84-85.

33 SARTORI, Giovanni. ¿Qué es la democracia? Colombia, Altamir, 1994, p. 23.
} 
embargo, ese a priori puede ser cuestionado. Un buen primer paso para hacerlo es agregar un tercer elemento, cual es, la elección popular como mayor expresión de la democracia, advirtiendo que su funcionamiento moderno dista mucho del concepto clásico. De la demokratía de los griegos a la política de masas de hoy hay una distancia nada despreciable. Para efectos prácticos consideraremos que "los sistemas democráticos modernos se apoyan sobre reglas mayoritarias (el mandato es de quien obtiene más votos y el mando es ejercido por quien detenta más curules en el parlamento), sobre mecanismos electivos y sobre la transmisión representativa del poder"34.

Cuestionar la sinonimia entre elección popular y democracia no es tarea fácil, mas no faltan las voces que se han atrevido a hacerlo. Bernard Manin se dio a la tarea de exponer cómo, cuando de elegir se trata, los votantes se inclinan hacia personas con cierto nivel educativo, cultural, y hasta patrimonial, y las experiencias que no siguen ese patrón son relativamente pocas ${ }^{35}$, por lo que la posibilidad de resultar elegido disminuye para aquellas personas provenientes de sectores sociales que no se acomodan a las exigencias de educación, cultura, y patrimonio de los votantes. Por otra parte, la libertad de que gozan los ciudadanos al acudir a las elecciones para escoger a uno u otro candidato es manipulable y en esto la publicidad juega un papel fundamental; y aquél que puede destinar más recursos a la financiación de su campaña electoral o que cuenta con la simpatía de los medios de comunicación, tiene una ventaja considerable frente a sus contendores y por consiguiente se multiplican sus posibilidades de triunfo ${ }^{36}$. La creciente influencia de la publicidad corre paralelamente a la apatía de la ciudadanía hacia la cosa política. "Los ciudadanos mismos se hunden cada década más en una ignorancia y apatía cívica cuidadosamente inculcada por la industria cultural y la manipulación política, evolucionando exactamente hacia el inverso de los sujetos bien educados y políticamente activos que hubiera debido ser la base humana de una democracia representativa" 37 .

\footnotetext{
${ }^{34}$ Ibid., p. 21.

${ }^{35}$ Manin recoge la experiencia estadounidense alrededor de las discusiones entre federalistas y antifederalistas en 1776, ad portas de la adopción de la Constitución de ese país. Para los antifederalistas la representación prevista por la Constitución se inclinaría a favor de las clases más prósperas y prominentes, de modo que, pese a que denunciaron esta tendencia aristocrática, no desarrollaron una explicación detallada que pudiera ser empleada en los debates públicos sobre las razones por las cuales solo los ricos y prominentes serían elegidos. Los federalistas aceptaban (aun sin entender exactamente porqué) que el pueblo, como regla, opta libremente por elegir a candidatos con patrimonio o respetables, así que defendieron la Constitución en términos de que ésta proporciona todas las garantías para que los representantes no traicionen la confianza del pueblo. MANIN, Bernard. Los Principios del Gobierno Representativo. Madrid, España, Alianza, 1998, pp. 141-156.

La posición de los federalistas queda clara en El Federalista LVII: “QQuiénes van a ser los electores de los representantes federales? (...) la gran masa del pueblo americano (...) ¿Quiénes van a ser objeto de la elección popular? Cualquier ciudadano cuyo mérito lo señale a la estimación y la confianza de su país. Ningún requisito de riqueza, cuna, fe religiosa o profesión civil puede poner trabas al juicio ni defraudar la inclinación del pueblo. Si consideramos la situación de los hombres a los que el libre sufragio de sus conciudadanos puede conferir un mandato representativo, hallaremos que ofrece todas las seguridades que pueden desearse o idearse para asegurar que son fieles a sus electores". Veáse así: MADISON, Santiago y Hamilton, Alejandro. El Federalista LVII. En: Hamilton Alejandro, Madison Santiago y JAy Juan. El Federalista. Primera edición en español, tercera reimpresión, México, Fondo de Cultura Económica, 1982, p. 243.

${ }^{36}$ Para María Luisa Rodríguez Peñaranda las probabilidades que tiene un candidato de ganar en los comicios aumentan en forma directamente proporcional a la divulgación de su candidatura, “(...) a mayor capacidad de difusión mediática de un candidato, mayores posibilidades de recordación tendrá entre los ciudadanos y, por tanto, mayores posibilidades de destacarse por algún rasgo de su perfil que le otorgue superioridad a juicio de sus electores". En RodríGUEZ PEÑARANDA, María Luisa. op.cit (n. 12).p. 21.

37 Anderson, Perry. "La evolución política de Norberto Bobbio". En: GonZALEZ, José M y QueSADA, Fernando, (coordinadores). Teorías de la Democracia. Segunda edición, España, Universidad Autónoma Metropolitana, Editorial Anthropos, 1992, p. 33.
} 
Una vez conformado el Congreso empieza a abrirse una brecha entre el elector y el elegido, apareciendo los partidos políticos como actores de la política ${ }^{38}$. Conforme la sociedad se fue haciendo más compleja los electores se organizaron en sectores identificados con ciertas ideas, lo cual representó el elemento que la democracia necesitaba para adaptarse a las necesidades de la vida moderna ${ }^{39}$. Las ventajas de la formación de partidos políticos son muchas, pero eso no oculta el hecho de que la relación representante-ciudadano es reemplazada por la relación representante- partido $^{40}$.

Además de esa distancia, John Ely describe otro problema y es el relativo a que "la elección popular significará relativamente poco si no sabemos qué hacen nuestros representantes" 41 . Se trata de la distorsión entre las funciones que debería desempeñar un representante una vez ocupa su curul y las que realmente realiza. La mayor parte del tiempo el representante no está dedicado a la realización de leyes sino a complacer los favores de sus electores que no tienen que ver precisamente con proponer y discutir iniciativas legislativas; pero esto el autor no lo interpreta en el sentido peyorativo de los términos y más bien se muestra benévolo al considerar que no por ello puede concluirse que los asuntos sustantivos no tengan cabida en el Congreso, sino que se tocan y expresan bajo formas diferentes, además de que el volumen de trabajo de los representantes les obliga a ello ${ }^{42}$.

Así, el funcionamiento del Congreso incluye personas de origen no democrático que están efectivamente involucradas con el proceso legislativo, pero el peligro de esta verdad no está en que ellos hagan mal su trabajo sino en que releven de él a quienes sí les corresponde esa labor. Al respecto, Ely señala que:

"no tiene mucho sentido preocuparse por la distribución del sufragio y otros derechos políticos personales a menos que las decisiones políticas de importancia sean adoptadas por funcionarios elegidos" 43 .

\footnotetext{
${ }^{38}$ Hay quienes diferencian entre electores y afiliados al partido político: "En este ámbito se plantea uno de los problemas más importantes de todo partido político, (...) Los miembros del partido, en sus funciones político-institucionales resultado de las elecciones, deben su mandato constitucional a los electores y no a los afiliados, asi que deben responder a aquellos que los eligieron y no pueden consultar cada decisión que ban de tomar con el partido y sus miembros voluntarios. En tanto que el modelo partidista supone que los líderes responden a sus afiliados y a los órganos del partido". Alcantara, Manuel y Freidenberg, Flavia. "Organización y funcionamiento interno de los partidos políticos en América Latina”. En su: Partidos Políticos de América Latina. México, Fondo de Cultura Económica de México, 2003, p.19.

${ }^{39}$ Para Maurice Duverger los partidos políticos se perfilan como grandes protagonistas de la democracia moderna, y su desarrollo “(...) aparece ligado al de la democracia, es decir, a la extensión del sufragio popular y de las prerrogativas parlamentarias; (...) cuanto más se extiende y multiplica el derecho al voto, más necesario se hace organizar a los electores a través de comités capaces de dar a conocer a los candidatos y de canalizar los sufragios en su dirección (...)”. DUverger, Maurice. Los Partidos Políticos. $17 \mathrm{ma}$ edición. México, Fondo de Cultura Económica de México, 2001, pp. 15-16.

${ }^{40}$ RODRÍGUEZ PEÑARANDA, María Luisa. Minorías, op.cit (n. 12), pp. 55-56. En sentido parecido se ha manifestado Germán Ruiz Páez al señalar que "el fortalecimiento de la representatividad y legitimidad del Congreso de la República es inseparable del fortalecimiento y modernización de los partidos", de modo que es fundamental que éstos "contemplen en su funcionamiento interno la participación efectiva de simpatizantes y miembros en forma permanente". Lo anterior da paso a la constante aspiración de democratización de los partidos políticos, medida que redundará en la legitimidad del Congreso de la república y en la percepción social del funcionamiento de la democracia. RUIZ PAEZ, Germán. "La Democratización de los Partidos Políticos en Colombia”, en Debate Político, Número 17, 2006: pp. 20-24.

${ }^{41}$ ELY, John Hart. op.cit (n. 18), p. 155.

42 Ibid., p. 156.

${ }^{43}$ Ibid., p. 158.
} 
La razón es que frecuentemente por el Congreso pasan asuntos que para los congresistas no es conveniente decidir en términos de que pueden resultar demasiado costosos políticamente por suscitar controversias, y los políticos están conscientes de ello.

Ante esto podría replicarse que la facultad de llamar expertos para conceptuar y ayudar en sus labores no es privativa de la administración, pues el Congreso también puede hacerlo. En efecto, los asuntos que decide el Congreso suelen ser técnicos y a menudo es necesaria la opinión de personas ajenas a la institución, pero su intervención debe entenderse como una labor de ilustración al congresista, quien luego de recibir la información podrá usarla para apoyar una iniciativa o hundirla. Radicar la responsabilidad de legislar en esas personas no elegidas representa, pues, una lesión a la democracia, en el sentido de negar la responsabilidad de legislar. En palabras de Ely "no es democrático, en el sentido bastante obvio de que al negarse a legislar, nuestros legisladores están eludiendo el tipo de responsabilidad que resulta crucial para el funcionamiento inteligible de una república democrática"44.

Esta visión pesimista de la democracia deja a un lado la posibilidad de que la ciudadanía ejerza control político sobre sus representantes, pero no es más optimista darse cuenta de que si los votantes están inconformes con la labor del Congresista tendrán que esperar a las próximas elecciones para votar en uno u otro sentido, y el control político tendría lugar solo en el momento previo al periodo legislativo o posteriormente, mas no durante el mismo. En estas condiciones es ingenuo pensar que castigar en las urnas a un representante que no cumplió a cabalidad su labor es tarea fácil, pues los medios de comunicación vuelven a tener protagonismo y es posible que el candidato no esté siquiera interesado en ser reelegido. El representante ya no se siente políticamente responsable.

Concluyendo parcialmente, tratándose de democracia representativa lo ideal es que todos los sectores sociales estén representados, y el Congreso sería una suerte de espacio deliberativo múltiple cuya producción legislativa está validada por un consenso en donde todos los intereses sociales han sido escuchados. "La teoría de la representación, en la que se basan las democracias modernas, tiene que descansar forzosamente en el pluralismo político y social que es propio de toda sociedad libre. Y ello se tiene que traducir no solo en la composición de los actuales Parlamentos, los cuales son el órgano por excelencia de la representación nacional o popular, sino también en su funcionamiento" 45 . Si la ley no es aprobada en las anteriores condiciones, sufre una reducción en su legitimidad por provenir de un Congreso cuya conformación fue precedida por prácticas que no se identifican con la democracia, lo cual redunda en esfumar, o al menos diluir, la idea del Parlamento representativo.

4. La corrección funcional y el stare decisis. Alternativas de legitimidad para el control constitucional.

${ }^{44}$ Ibid., p. 162.

45 SÁnCHeZ Navarro, Ángel. Las Minorias en La Estructura Parlamentaria, Madrid, España, Centro de Estudios Constitucionales, 1995, p. 20. 
Aunque las anteriores críticas a la legitimidad del Parlamento no son volátiles, la democracia ha sido aceptada como la forma de gobierno que se adapta con más o menos precisión a las intenciones de la ciudadanía y es percibida de manera general como equitativa y legítima. De todos modos, las objeciones anotadas no evitan que al comparar al Tribunal con el Congreso en cuanto a la génesis de su conformación el primero siga estando en desventaja. En efecto, el modo de designación de los miembros del Tribunal está precedido de un proceso político elitista y cerrado si se le compara con el del Congreso ${ }^{46}$; pero la crisis de representatividad que éste atraviesa no justifica automáticamente las decisiones del Tribunal, pues ello equivaldría a hacer de los Tribunales Constitucionales los grandes realizadores de la justicia social, y del control constitucional su principal arma.

Todo parece indicar que la democracia debe ser valorada en sus justas proporciones, y si bien democracia y legitimidad por regla general se asocian, la democracia no es necesariamente fuente obligada de legitimidad. "La legitimidad no puede medirse bajo la égida de un concepto sesgado de democracia"47, y en cambio puede buscarse en otras fuentes que se articulen con mayor propiedad a las funciones encomendadas al Tribunal Constitucional. Con esto volvemos la mirada hacia la interpretación; y específicamente, al grado de responsabilidad con que el Tribunal lleve a cabo esa función.

Volviendo sobre nuestros pasos, el control constitucional es una labor de interpretación, en la cual el juez constitucional se debate entre la dignidad democrática de la ley y la necesidad de dotar de contenidos a la Constitución. Consciente de esto, Konrad Hesse sugiere un elenco de principios que ayudarían al juez en su labor y quizá el mas notable de ellos sea el principio de corrección funcional. Después de todo, "a los principios-dice Hesse- les corresponde la misión de orientar y encauzar el proceso de relación, coordinación y valoración de los puntos de vista o consideraciones que deben llevar a la solución del problema"48.

Según la corrección funcional, el órgano de interpretación debe mantenerse dentro del marco de las funciones a él encomendadas. "Esto es aplicable en particular a las relaciones entre legislador y Tribunal Constitucional: puesto que al Tribunal Constitucional solo le corresponde frente al legislador, una función de control, le está vedada una interpretación que condujese a una restricción de la libertad conformadora del legislador más allá de los límites establecidos por la Constitución o, incluso, a una conformación llevada a cabo por el Tribunal mismo"49.

\footnotetext{
46 Para Charles Evans Huges ni los Magistrados ni el Tribunal Constitucional pierden validez por no estar su origen asociado a una elección popular; al contrario, exalta a la Corte Suprema de los Estados Unidos en función de "la calidad de los hombres seleccionados y las restricciones impuestas por los principios que adoptaron para el control de su ejercicio del poder judicial. (...) Si se coloca en los Tribunales a hombres conscientes, escrupulosos, capaces e independientes, nadie podrá predecir-tomando como punto de referencia sus motivos partidistas o sus lealtades políticas o personales- la conducta que observarán como jueces". HuGES, Charles Evans. La Suprema Corte de los Estados Unidos. Segunda edición, México D.F, Fondo de Cultura Económica, 1971, pp. 53- 69. Igualmente, García de Enterría asegura que "los jueces tienen la legitimidad del derecho que están llamados a aplicar; su independencia es la expresión misma de la objetividad de ese Derecho; nada añadiría a su función una designación electiva". GARCIA DE ENTERRIA, Eduardo. Democracia, Jueces y Control de la Administración. Quinta edición. España, Civitas Ediciones, 2000, p. 34.

47 Rojas Marroquin, Abdón Mauricio y Patron Perez, Daniel Eduardo. "El segundo reparo antidemocrático de la justicia constitucional". En: SANIN ReSTREPO, Ricardo. Justicia Constitucional. El Rol de la Corte Constitucional en el Estado Contemporáneo. Colombia, Editorial Legis, 2006, p. 228.

${ }^{48}$ Hesse, Konrad. op.cit (n. 7). pp. 47-48.

${ }^{49}$ Ibid. p. 50. Por otra parte, esta fórmula como camino para superar la objeción democrática no escapa a ciertas críticas, pues aunque "se respeta las decisiones del legislador, disminuyendo al minimo la interferencia de las interpretaciones constitucionales en la libertad de
} 
Este principio se entiende como una exhortación constante al juez constitucional a respetar la democracia como valor social, y le insta a no olvidarlo mientras realiza el control constitucional. Está para recordarle que después de todo, se encuentra ante una ley que es producto del consenso, y lesionarla resultaría demasiado costoso en términos sociales, por lo que, de sentirse tentado, deberá considerarlo con mayor detención.

Hasta aquí hemos retomado el respeto a la ley democráticamente aprobada como elemento aportado por el Tribunal Constitucional Alemán y por la teoría de John Ely, y tendríamos un juez constitucional consciente de su importancia y cuidadoso de ella. Sin embargo, respeto podría confundirse con inercia, y en tal caso, la ley se transformaría en algo tan inaprensible que podría convertir al Tribunal Constitucional en un verdadero convidado de piedra, y al control constitucional en una figura poco efectiva.

Para que un Tribunal Constitucional trace sus lineamientos y defina con la mayor precisión posible el límite entre interpretar la Constitución e irrespetar los procesos democráticos que legitiman la ley, debe siempre hacerlo a través del tiempo, y el common law ha entendido esto al darle especial importancia a la regla del precedente judicial ${ }^{50}$. "Una vez [que] una decisión ha sido tomada, la misma debe ser proferida en todos los casos de especie similar por todas las jurisdicciones. (...) En casos muy excepcionales, la jurisdicción suprema puede cambiar la jurisprudencia" 51 siempre que este cambio pueda ser explicado suficientemente mediante una juiciosa argumentación jurídica, pues la estricta y razonada argumentación de sus sentencias constituye sostén inobjetable de legitimidad de la Corte Constitucional ${ }^{52}$.

Si al juez constitucional, aún teniendo presente el principio de corrección funcional, lo asaltan dudas sobre el momento en el cual excede el límite entre interpretar la Constitución y guardar la jurisdicción constitucional; y simplemente lesionar la democracia, los parámetros sentados por los pronunciamientos jurisprudenciales anteriores le servirán de guía. De esa forma, el delicado equilibrio que el Tribunal debe sostener entre respetar la democracia y ejercer su labor interpretativa; entre obedecer el precedente y distanciarse de él mediante una argumentación estable 53 ; entre observar el principio de corrección funcional e incluir el stare

configuración politica del legislador'. Este tipo de argumento ha llevado a la Corte Constitucional (Tribunal Constitucional) a denegar tutelas (recursos de amparo) y recanalizar las pretensiones de los demandantes a las vías politicas regulares. Se trata, incluso, de peticiones que la Corte (Tribunal Constitucional) encuentra razonables y justas, pero la judicatura se niega a conceder como derechos. La teoría constitucional ha denominado esta noción self-restrint, auto-restricción: son casos en los cuales el juez desearía poder fallar porque cree que la justicia demandaría una solución diferente, (...) acepta, en contra de sus deseos, que se trata de una justicia que debe tramitarse por los canales políticos y no en los estrados judiciales. Se trata, por asi decirlo, de justicia legislativa y no de justicia judicial”. LOPEZ MEDINA, Diego Eduardo. El Derecho de los Jueces. Segunda edición, Colombia, Legis Editores S.A., 2006, p. 328.

${ }^{50}$ Esta regla ha sido entendida como presupuesto del advenimiento de la justicia constitucional: "La Corte entendió que su agenda emancipadora estaba intimamente conectada con el establecimiento de un mecanismo de precedentes que asegurara la aplicación masiva y disciplinada, en primera instancia, de sus sentencias y fallos". LOPEZ MEDINA, Diego Eduardo. op.cit (n. 49), p. 326.

51 GARAPON Antoine y PAPADOPOULOS Ioannis. Juagar en Estados Unidos y en Francia, Cultura Jurídica Francesa y Common Law. Colombia, Editorial Legis, 2006, pp. 35-36.

52 Rojas Marroquin, Abdón y Patron Perez, Daniel Eduardo. op. cit. (n. 47). Así mismo, Manuel Atienza señala que: “en el contexto del derecho moderno, en el que la obligación que se establece de motivar-justificar-las decisiones, no solo contribuye a hacerlas aceptables (y esto resulta especialmente relevante en sociedades pluralistas que no consideran como fuente de legitimidad o de consenso cosas tales como la tradición o la autoridad), sino también a que el derecho pueda cumplir su función de guía de la conducta bumana". ATIENZA, Manuel. Las razones del Derecho. Primera edición, Segunda reimpresión. México, UNAM, 2005, pp. 7-8.

53 Para Joseph Raz un buen ejercicio de interpretación jurídica no es posible en un derecho discontinuo, así que la continuidad en el derecho es presupuesto fundamental de la interpretación jurídica. Dice Raz "La importancia de la continuidad en el derecho se manifiesta, mas que nada, por dos características centrales. Primero está el hecho de que tanto la legislación como los precedentes se mantienen obligatorios mucho después de que sus autores han perdido el poder. La vida del derecho no está vinculada por la vida de los creadores del derecho. Esto da al derecho 
decisis como derrotero de su labor, contribuye a realizar la legitimidad del control constitucional.

\section{Conclusión.}

La aproximación a la legitimidad del control constitucional en las democracias disfuncionales por parte del juez constitucional, tendrá lugar en tanto el juez constitucional sostenga su labor sobre el principio de corrección funcional y sobre el stare decisis. El Tribunal Constitucional será legítimo si es percibido por la cultura jurídica como una institución sólida de criterios jurídicos bien cimentados, cuyos miembros demuestran mediante su producción jurisprudencial suficiente manejo de la argumentación jurídica y un profundo conocimiento del Derecho. Si las construcciones conceptuales del Tribunal Constitucional se muestran débiles ante el más mínimo cuestionamiento; si las sentencias se suceden las unas a las otras sin guardar coherencia en sus líneas interpretativas y argumentativas; si es evidente el irrespeto injustificado de la producción jurídica actual por la de antaño y los criterios de decisión parecen extraordinariamente sujetos a coyunturas políticas e intereses personales, será inevitable pensar que se está ante un Tribunal ilegítimo cuyo ejercicio del control constitucional es injustificable en la democracia.

\section{REFERENCIAS BIBLIOGRAFICAS}

ACKERMAN, Bruce. La Politica del Diálogo Liberal. España, Editorial Gedisa, 1999.

ALCANTARA, Manuel y FREIDENBERG, Flavia. Organización y funcionamiento interno de los partidos políticos en América Latina. En su: Partidos Políticos de América Latina. México, Fondo de Cultura Económica de México, 2003.

ALVAREZ ALVAREZ, Fernando D. Legitimidad Democrática y Control Judicial de Constitucionalidad (Refutaciones Al Denominado Carácter Contramayoritario Del Poder Judicial) Revista de actualidad jurídica Díkaion. <En línea $>$. Facultad de Derecho, Universidad de La Sabana, número 12, 2003. Disponible en la World Wide Web: $<$ http:/ dialnet.unirioja.es/servlet/articulo?codigo $=2107653>$.

ANDERSON, Perry. La evolución politica de Norberto Bobbio. En: GONZALEZ, José M y QUESADA, Fernando, (coordinadores). Teorías de la Democracia. Segunda edición, España, Universidad Autónoma Metropolitana, Editorial Anthropos, 1992.

un considerable grado de continuidad”. RAZ, Joseph. “¿Porqué interpretar?”, en Isonomía. Revista de Teoría y Filosofía del Derecho. [En línea]. Volumen 5: 34, 1996. Disponible en la World Wide Web:

<http://www.cervantesvirtual.com/servlet/SirveObras/02405065325240496976613/isonomia05/isonomia5_02.pdf> 
ATIENZA, Manuel. Las razones del Derecho. Primera edición, Segunda reimpresión. México, UNAM, 2005.

BÉGUIN, Jean-Claude. Le Contròle de la Constitutionnalité des lois en République Fédérale d'Allemagne. En: FERNÁNDEZ SEGADO, Francisco. Evolución Histórica y Modelos de Control de Constitucionalidad. En: GARCIA BELAUNDE, D. y FERNÁNDEZ SEGADO, F. (coordinadores). La Jurisdicción Constitucional en Iberoamérica. Madrid, Editorial Dykinson, 1997.

BICKEL, Alexander. The Least Dangerous Branch. En: FERRERES COMELLA, Víctor. Justicia Constitucional y Democracia. Madrid, Centro de Estudios Políticos y Constitucionales, 1997.

CARRILLO FLORES, Antonio. Prologo a la primera edición. En: HUGES, Charles Evans. La Suprema Corte de los Estados Unidos. Segunda edición en español, México D.F, Fondo de Cultura Económica, 1971.

DUVERGER, Maurice. Los Partidos Políticos. 17ma edición. México, Fondo de Cultura Económica de México, 2001.

ELY, John Hart. Democracia y Desconfianza, Una Teoría del Control Constitucional. Bogotá, Colombia, Siglo del Hombre Editores, Universidad de los Andes, 1997.

FERRERES COMELLA, Víctor. Justicia Constitucional y Democracia. Madrid, España, Centro de Estudios Políticos y Constitucionales, 1997.

GARAPON Antoine y PAPADOPOULOS Ioannis. Juzgar en Estados Unidos y en Francia, Cultura Jurídica Francesa y Common Law. Colombia, Editorial Legis, 2006.

GARCIA DE ENTERRIA, Eduardo. Democracia, Jueces y Control de la Administración. Quinta edición. España, Civitas Ediciones, 2000.

, Eduardo. La Constitución como norma y el Tribunal Constitucional. Tercera edición, Madrid, España, Editorial Civitas, S.A., 1985.

GARGARELLA, Roberto. La Justicia frente al Gobierno. Sobre el carácter contramayoritario del poder judicial. Barcelona, Editorial Ariel S.A, 1996.

GONZALEZ SOLANO, Edgar. Sentencias Manipulativas e Interpretativas y Respeto a la Democracia en Colombia. Colombia, Universidad Externado de Colombia, 2000.

HESSE, Konrad. La Interpretación constitucional. En sus: Escritos de Derecho Constitucional. Primera edición al español, Madrid, España, Centro de Estudios Constitucionales, 1983. 
HUGES, Charles Evans. La Suprema Corte de los Estados Unidos. Segunda edición, México D.F, Fondo de Cultura Económica, 1971.

KELSEN, Hans. ¿Quién debe ser el defensor de la constitución? Segunda edición, España, Editorial Tecnos, 1995.

LANDA ARROYO, Cesar. Justicia Constitucional y Political Questions. Revista Pensamiento Constitucional. <En línea> Volumen 7, número 7, 2000. Disponible en la World Wide Web: $<$ http://www.pucp.edu.pe/revista/pensamiento_constitucional/?art01.htm>

LOPEZ DAZA, Germán Alfonso. La Justicia Constitucional Colombiana: ¿Un gobierno de los Jueces? Colombia, Editorial Universidad Surcolombiana, 2005.

LOPEZ MEDINA, Diego Eduardo. El Derecho de los Jueces. Segunda edición, Colombia, Legis Editores S.A., 2006.

MADISON, Santiago y HAMILTON, Alejandro. El Federalista LVII. En: HAMILTON Alejandro, MADISON Santiago y JAY Juan. El Federalista. Primera edición en español, tercera reimpresión, México, Fondo de Cultura Económica, 1982.

MANIN, Bernard. Los Principios del Gobierno Representativo. Madrid, España, Alianza, 1998.

POUND, Roscoe. El Espiritu del Common Law. Barcelona, España, Casa editorial Bosch, 1954.

RAZ, Joseph. ¿Porqué interpretar?, en Isonomía. Revista de Teoría y Filosofía del Derecho. $<$ En línea>. Volumen 5: 34, 1996. Disponible en la World Wide Web: <http://www.cervantesvirtual.com/servlet/SirveObras/02405065325240496976613/isonomi a05/isonomia5_02.pdf $>$

RESTREPO PIEDRAHITA, Carlos. Esquicio para una perspectiva bistórica del Congreso en Colombia. Bogotá, Universidad Externado de Colombia, 1986.

RODRÍGUEZ PEÑARANDA, María Luisa. Minorías, Acción Pública de Inconstitucionalidad y Democracia Deliberativa. Colombia, Universidad Externado de Colombia, 2005.

ROJAS MARROQUIN, Abdón Mauricio y PATRON PEREZ, Daniel Eduardo. El segundo reparo antidemocrático de la justicia constitucional. En: SANIN RESTREPO, Ricardo. Justicia Constitucional. El Rol de la Corte Constitucional en el Estado Contemporáneo. Colombia, Editorial Legis, 2006.

ROJAS MARROQUIN, Abdón y PATRON PEREZ, Daniel Eduardo. El segundo reparo antidemocrático de la justicia constitucional. En: SANIN RESTREPO, Ricardo. Justicia Constitucional. El Rol de la Corte Constitucional en el Estado Contemporáneo, Colombia, Editorial Legis. 2006. 
RUIZ PAEZ, Germán. La Democratización de los Partidos Políticos en Colombia, en Debate Político, Número 17, 2006.

SÁNCHEZ NAVARRO, Ángel. Las Minorías en La Estructura Parlamentaria, Madrid, España, Centro de Estudios Constitucionales, 1995.

SARTORI, Giovanni. ¿Qué es la democracia? Colombia, Altamir, 1994.

SCHWABE, Jürgen. Cincuenta Años de Jurisprudencia del Tribunal Constitucional Federal Alemán. Bogotá, Ediciones Jurídicas Gustavo Ibáñez, 2003. 